\title{
GCU
}

Glasgow Caledonian

University

University for the Common Good

\section{Developing a framework for underground cable fault-finding in low voltage distribution networks}

Ali, Khalif H.; Bradley, Stephen ; Aboushady, Ahmed A.; Abdel Maksoud, Salah A.; Farrag, Mohamed E.

Published in:

2020 9th International Conference on Renewable Energy Research and Application (ICRERA)

DOI:

10.1109/ICRERA49962.2020.9242813

Publication date:

2020

Document Version

Author accepted manuscript

Link to publication in ResearchOnline

Citation for published version (Harvard):

Ali, KH, Bradley, S, Aboushady, AA, Abdel Maksoud, SA \& Farrag, ME 2020, Developing a framework for underground cable fault-finding in low voltage distribution networks. in 2020 9th International Conference on Renewable Energy Research and Application (ICRERA). IEEE, pp. 477-482, 9th International Conference on Renewable Energy Research and Applications, 27/09/20. https://doi.org/10.1109//CRERA49962.2020.9242813

\section{General rights}

Copyright and moral rights for the publications made accessible in the public portal are retained by the authors and/or other copyright owners and it is a condition of accessing publications that users recognise and abide by the legal requirements associated with these rights.

Take down policy

If you believe that this document breaches copyright please view our takedown policy at https://edshare.gcu.ac.uk/id/eprint/5179 for details of how to contact us. 


\section{GCU}

Glasgow Caledonian

University

University for the Common Good

\section{Developing a Framework for Underground Cable Fault-Finding in Low Voltage Distribution Networks}

Ali, Khalif; Bradley, Stephen ; Aboushady, Ahmed; Abdel Maksoud, Salah; Farrag, M E A

Published in:

9TH INTERNATIONAL CONFERENCE ON RENEWABLE ENERGY RESEARCH AND APPLICATIONS

Publication date:

2020

Link to publication in ResearchOnline

Citation for published version (Harvard):

Ali, K, Bradley, S, Aboushady, A, Abdel Maksoud, S \& Farrag, MEA 2020, Developing a Framework for Underground Cable Fault-Finding in Low Voltage Distribution Networks. in 9TH INTERNATIONAL CONFERENCE ON RENEWABLE ENERGY RESEARCH AND APPLICATIONS.

\section{General rights}

Copyright and moral rights for the publications made accessible in the public portal are retained by the authors and/or other copyright owners and it is a condition of accessing publications that users recognise and abide by the legal requirements associated with these rights.

Take down policy

If you believe that this document breaches copyright please view our takedown policy at https://edshare.gcu.ac.uk/id/eprint/5179 for details of how to contact us. 


\title{
Developing a Framework for Underground Cable Fault- Finding in Low Voltage Distribution Networks
}

\author{
Khalif H. Ali ${ }^{1 *}$, Stephen Bradley ${ }^{2}$, Ahmed A. Aboushady ${ }^{1}$, Salah A. Abdel Maksoud ${ }^{1,3}$, Mohamed E. Farrag ${ }^{1}$ \\ ${ }^{1}$ School of Computing, Engineering and Built Environment, Glasgow Caledonian University, Glasgow, UK \\ ${ }^{2}$ Scottish Power Energy Networks (SPEN), Glasgow, UK \\ ${ }^{3}$ Dept. of Electrical Power Engineering, Faculty of Engineering, Port-Said University, Port-Said, Egypt
}

*Corresponding author: khalif.ali2@gcu.ac.uk

\begin{abstract}
This work presents a guide for practitioners based on analysis of the fault-finding technologies used by Scottish Power Energy Networks (SPEN - one of the largest UK energy companies) for underground cables in the LV distribution network. The study involves looking at the methods and processes used with the purpose of identifying the strengths, weaknesses, opportunities and technologies within SPEN's fault-finding division. The research was achieved by a literature study as well as through numerous site visits to assess real life fault-finding scenarios. The study revealed that there was a lack of a designated $L V$ fault-finding process based on a structured protocol, accordingly a framework was developed to create a methodical approach. This is presented in the form of a flowchart showing different scenarios of faults and their respective finding procedures. The proposed framework aims to streamline the $L V$ fault-finding procedure for practitioners with the ultimate objective of helping utilities ensure a reduction in customer interruptions and customer minutes offline, to improve network reliability.
\end{abstract}

Keywords-Cable failure, Fault-finding, LV distribution network, Underground power cables.

\section{INTRODUCTION}

Faults occurring in underground power cables bring a plethora of socio-economic problems due to the loss of supply or hazards of electroshocks. Compromised cables can result in currents leaking from the cable and may cause electroshocks to people, animals and nearby infrastructure due to conduction. Electroshocks can vary in severity; from minor shocks to injuries and even death, but they can also cause explosions if the faults cause arcing near leaking gas pipes [1]. Loss of supply is made of two main segments; Customer Interruptions (CIs) and Customer Minutes Lost (CMLs), and loss of supply to customers results in the payment of large fines by Distribution Network Operators (DNO's) like Scottish Power Energy Networks (SPEN) to regulation authority Ofgem. Hence, finding faults quickly and accurately in underground power cables is crucial for ensuring safety to the public, securing supply to customers and reducing expensive penalty fees [2].

An independent risk management and quality assurance company called DNV GL (Energy) conducted a survey of around 170 individual cases of failures occurring with underground power cables in the Netherlands between 1994 and 2014 . The survey revealed that $37 \%$ of causes were from joint failures, $32 \%$ of causes were from termination failures, and $31 \%$ of causes were from the cables themselves. These results are very interesting because they show that $69 \%$ of faults occur from cable accessories rather than the cables themselves. The survey also showed that $52 \%$ of faults occurring with cables themselves were caused from cable production and installation i.e. due to manufacturing defects and poor quality of workmanship, whereas $17 \%$ of faults were due to external damages (third party inflictions) and $9 \%$ were due to cable ageing [3]. A similar picture is given to faults occurring with cable accessories; where $57 \%$ of faults were caused by installation errors. Figure 1 illustrates the ratios.
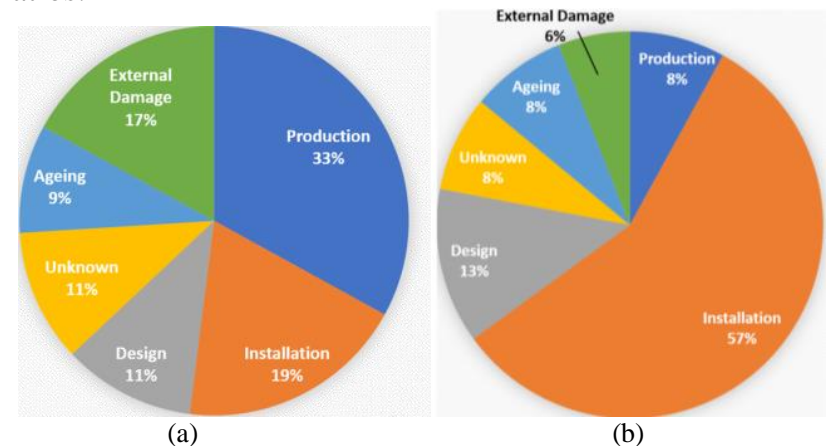

Figure 1. Percentage ratio of different causes of faults occurring in: (a) cables, (b) cable accessories [3]

The installment of the underground infrastructure in UK peaked in the 1950's and 1960's, therefore, a considerable proportion of cable assets have now reached the end of their expected design life [3]. The ageing effect causing cable failure occurs within the cable insulation and is due to a number of deteriorating factors that ultimately cause partial discharge and eventual failure [3,4]. Although some HV PILC cables that were installed in 1920's are still in healthy conditions, the increase of demand for electricity has reached near capacity limit and this has caused an increase of thermal stress on the cables $[3,5]$. As XLPE cables have a higher maximum operating temperature, excellent electrical properties and are relatively cheaper, they have become the new globally preferred cable. However, XLPE cables have shown to be susceptible to damage from fluctuating temperatures and environmental moisture, hence, if the cables are not installed with added protection (such as being placed in ducts), then they have accelerated failure rates and life expectancies of only 15-25 years [3,6-9].

Fault-finding in underground power cables can be very challenging due to their inaccessibility. There is plenty of literature discussing the effectiveness of available techniques and technologies such as [10-13]. Yet, the literature is addressing the technologies towards MV/HV cables only and the same technologies are not applicable to LV fault-finding. Many well established industrial companies such as Cigre and Megger have published brochures and structured guides on fault-finding procedures but most of the technologies, especially the most effective technologies, are not applicable 
to the LV network $[14,15]$. Rather, LV fault-finding is based on senior engineers practicing procedures from experience and then passing their knowledge from accumulated experience down to new recruits and so on.

Hence, there is a recognizable gap in available knowledge as well as effective technologies available for LV fault-finding.

This paper presents an insight into LV fault-finding and introduces the development of a framework for LV faultfinding in the distribution network. Section II provides a description of the main technologies currently in use by utilities for LV fault-finding. Section III describes the main steps involved in the typical fault-finding process, Section IV introduces the proposed framework for LV fault-finding in the distribution network and Section $\mathrm{V}$ provides a critical discussion of current and proposed practices. Finally, Section VI presents concluding remarks.

\section{LV FAULT-FINDING TECHNOLOGIES}

Contrarily to HV fault-finding, SPEN only utilize a handful of main equipment for LV fault-finding. A brief description of each technology is provided as following.

\section{A. Time Domain Reflectometry (TDR)}

Time domain reflectometer (TDR), also known as pulse echo or echo-meter, is a fault locator device. It is the most widely used pre-location method for LV faults within SPEN. TDRs used in LV, are portable handheld devices as shown in Figure 2(a). The TDR operates by sending low energy (around $50 \mathrm{~V}$ ) pulses into the faulty cable. Some energy from the signals get reflected back when they encounter a point of change of impedance within the cable. Hence, a map (trace) can then be made by calculating the distances from the time of the received reflected signals. The TDR works best with two particular types of faults; the first being a shunt fault with a resistance of less than a hundred ohms; and the second being an open circuit fault, because these conditions result in sufficient reflection for the TDR to recognize [14,15]. These conditions are best, as they give a clean reading, allowing for a more accurate pre-location of the fault. Figure 2(b) shows typical pulse reflection results for different fault types.

\section{B. The Sniffer Method}

The cable sniffer is a much more preferred method than resorting to the cut and test method which faces additional costs of almost $50 \%$. This technology works by sensing and analysing gases which emit by cable fault occurrences. The gases it detects are the gases given off by the breakdown of insulation during the fault, at the point of the fault. Small $8 \mathrm{~mm}$ holes are bored into the surface of the ground and the sniffer nozzle is inserted into a hole to detect and analyse the presence of any gases [16], this is shown in Figure 3. The sniffer analyses the gases in parts per millions $(50,000 \mathrm{ppm}=$ full scale deflection), a higher reading means a higher concentration of gas is detected. The concentration of gas detected will spike as is gets closer to the point of fault, thereby, pinpointing the location of the fault.

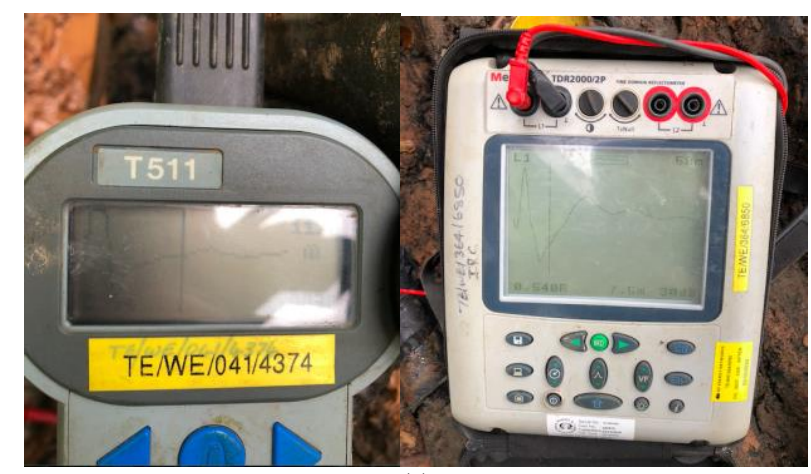

(a)
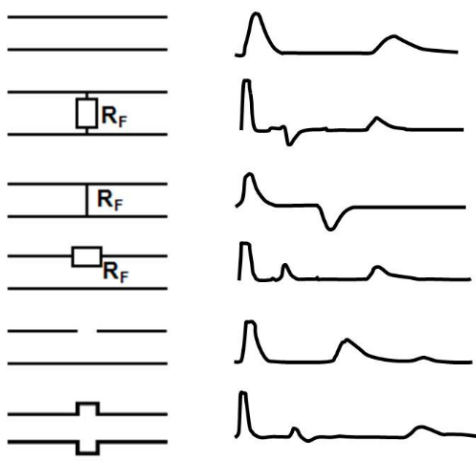

Cable without fault

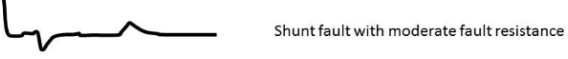

ح

n

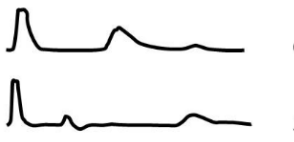

Shunt fault with low fault resistance

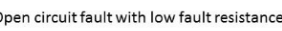

Open circuit fault with high fault resistance

(b)

Figure 2. Time Domain Reflectometers (TDR) Used in LV Network: (a) Typical devices used (b) Principle TDR pulse reflection results [14]

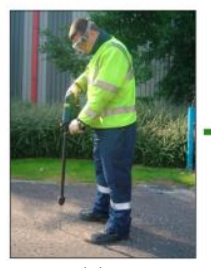

(a)

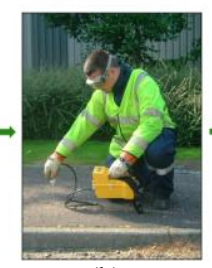

(b)

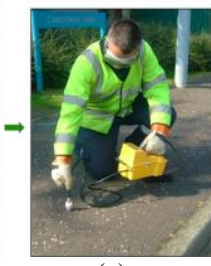

(c)

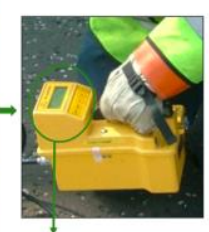

(d)
Figure 3. Process for Pinpointing Cable Faults Using Cable Sniffer Method: (a) Make a hole in the surface (b) Insert probe (c) Draw gas from below the surface (d) Sniffer analysis of gas

The sniffer is limited on the following circumstances; when the gas may have dissipated into the air by the time an approximated fault location has been determined; when the makeup of the ground does not allow gas to disperse to the surface; or when the insulation has not broken down enough to release a concentration of gas which can be detected [16].

\section{Cable Avoidance Tool (CAT)}

Although the CAT is not used to specifically locate faults, they do have an important function in tracing cable routes. The CAT is often used by the construction industry to determine the presence of any cables or pipes etc. underground before excavation is initiated (see Figure 4). The CAT is used in conjunction with a generator (often therefore called CAT and Genny) which generates power into underground cables that may be offline, so that the CAT is then able to detect them. The CAT operates by electromagnetically coupling with a cable's electromagnetic field. The tracking system is similar to that of the Sniffer device, i.e. the coupling from the cable is strongest when directly over the cable and weaker when further away. The 
expected route of a cable must be identified to accurately determine the position of a fault. Even though cable routes are identified through the use of cable records as well as tracing equipment, the cable records can only be used as an approximation on the location of the cable because the records often lack accuracy. The tracing equipment should then be used to confirm the exact location of the cable route $[15,17]$.

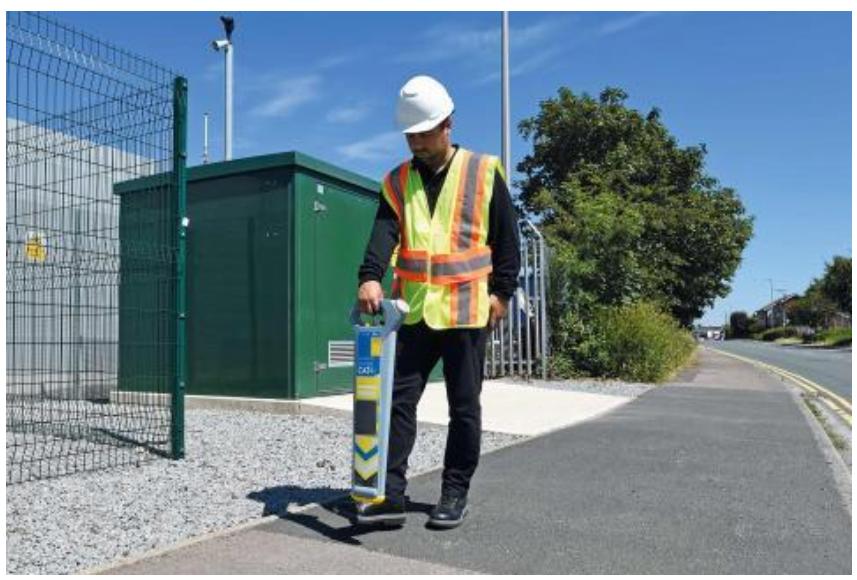

Figure 4. Cable Avoidance Tool (CAT)

\section{Cut and Test Method}

The cut and test method is outdated but still often a necessary option in SPEN fault finding practice, especially when the cable sniffer method is not successful. This method is used in two conditions; the first condition is when a positive prelocation can be determined with the use of a TDR and at the estimated point of fault the cable sniffer method is used, but if it cannot pinpoint the fault location then a cut and test is required (see Figure 5); the second condition is when there is no positive fault location given by the TDR and the only way of determining the location of the fault is by sectioning the circuit down until the location of the fault can be found (see Figure 6). Although the cut and test method is very reliable and has been in practice since the start of fault finding, this is not a desirable technique for SPEN in an economical perspective. The issue is that the cost of fault repair may greatly exceed the estimations due to the requirement of multiple excavations [15].

\section{FAULT-FInding PROCESS}

The fault repair procedure is a multiple step process which is initiated by the presence of a fault on the electrical network, as shown in Figure 7. This section discusses each step in the fault repair process with reflection on the procedures practiced by SPEN.

\section{A. Fault}

For the LV distribution network, the existence of a fault is first acknowledged by trouble calls from customers. Network operators rely solely on trouble calls from customers notifying them of power outages and a sufficient number of trouble calls can help approximate an affected area.
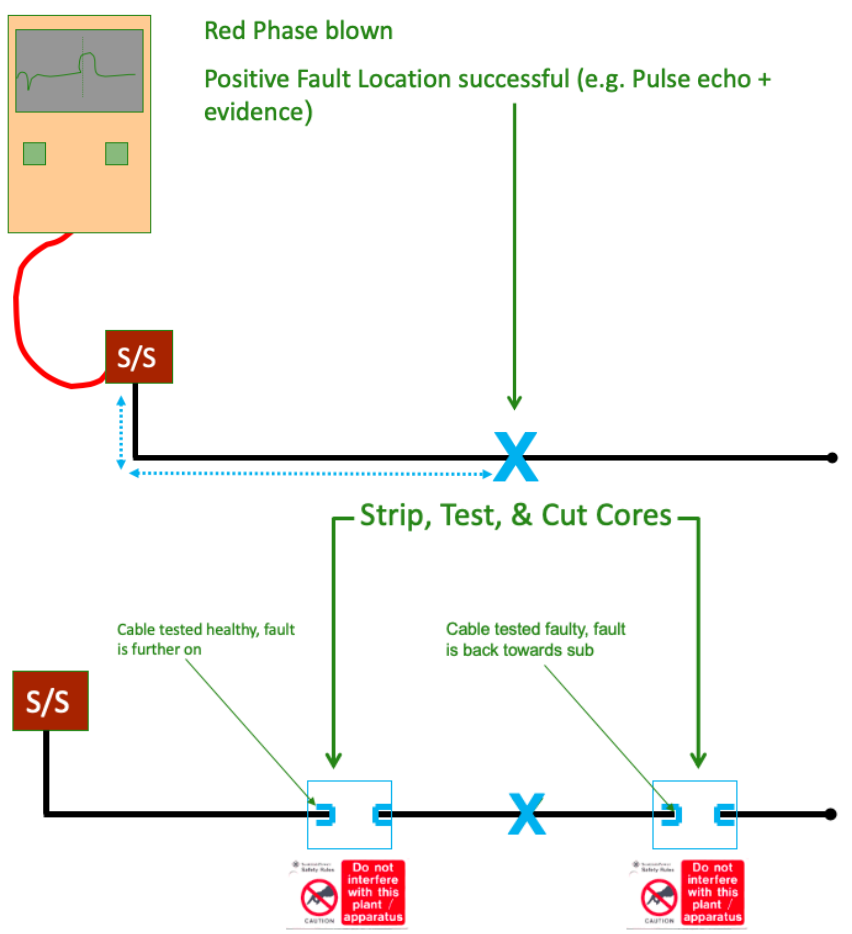

Figure 5. Cut and test method for fault-finding with positive fault location using TDR

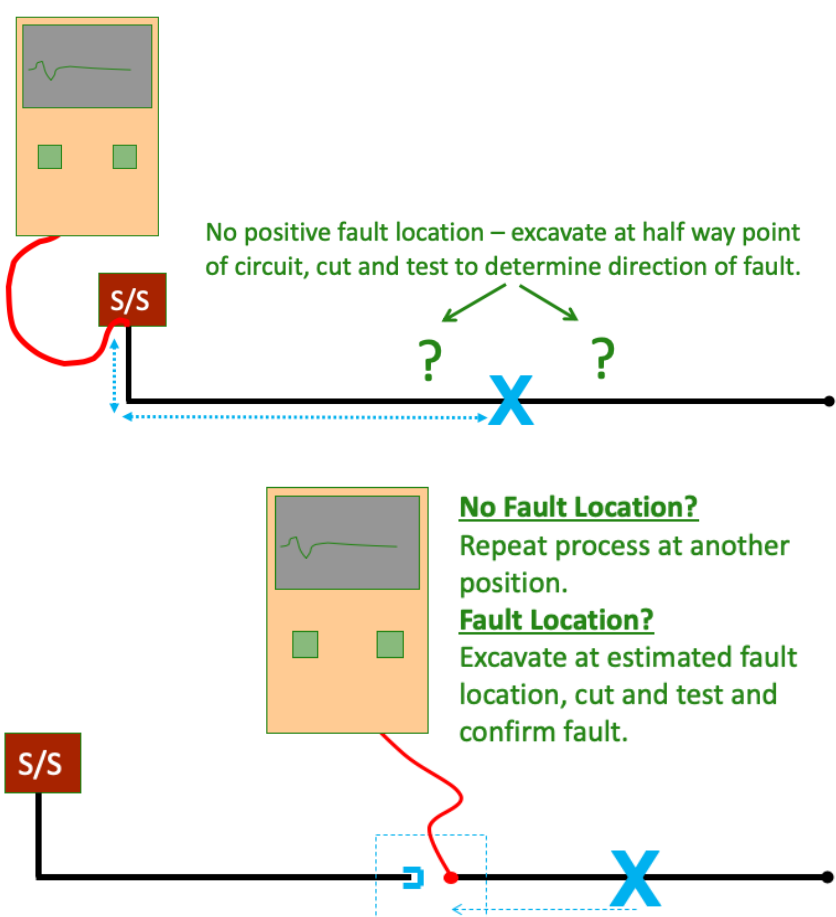

Figure 6. Cut and test method for fault-finding with no positive TDR fault location.

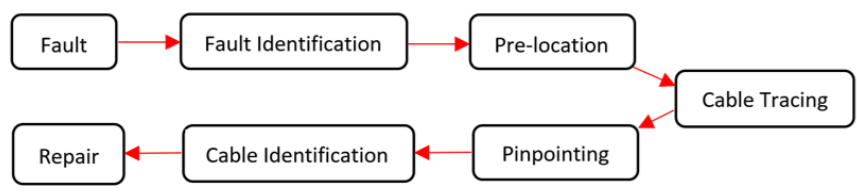

Figure 7. Fault repair procedure 
The operators narrow down the possible location of the fault by using maps and schematics of feeder configurations and positions of protective devices in conjunction with where the troubled customers are supplied from and what protective devices may have been involved in clearing the fault in the outage area. However, relying on trouble calls as a fault indicator is not always the best practice as delays in customer's information about the outage, false critical information, incomplete reports and delays in troubled calls with faults occurring during sleeping hours all present challenges to this method.

When a fault is identified by customers and confirmed to be on the network, resources are dispatched to locate and repair, although, sometimes this can be a tedious task if the area in which the fault has occurred has not been narrowed down to a small portion of the network. In these cases, determining the location of the fault is heavily dependent on the engineers having sufficient experience on the network as well as having a good knowledge and understanding of the area and in possession of adequate cable records. This method, albeit outdated, is still the main process adopted by SPEN for identifying a fault on the LV network.

\section{B. Fault Identification}

To identify what type of fault has occurred on the network (be it a sheath, open or a type of short circuit fault) testing must be carried out onsite by an engineer. Test lamps are predominantly used because they are applicable on live LV cables to identify blown fuses or dead cores, whereas, continuity and insulation resistance testing can only be done on cables which are offline.

\section{Pre-location}

The pre-location of the fault is imperative to reduce the time spent of pinpointing a fault. Cable fault location techniques are generally categorized into two sections, pre-location and pinpointing. Pre-location essentially involves testing cables from the remote ends of cable terminations to determine the distance to fault. The main technique used for the LV network is by time domain reflectometry (TDR). The fault in some cases will need to be conditioned if the fault resistance is too high because the TDR is limited to recognizing faults over $100 \mathrm{ohms}$. Conditioning involves passing large voltages and currents down the cable to break down the fault resistance by arcing, thereby, allowing for a better location of fault. A good pre-location can estimate a cable fault position within a small percentage of cable. In some larger underground cable sections however, the estimated fault location can be significantly off. This can be the result of incorrect cable mappings or a cable section made up of a variety of different cable types. The information gained from the pre-location is used to help pinpoint the exact location of the fault. Hence, the better the pre-location, the easier the pinpointing.

\section{Cable Tracing}

Tracing cable routes are an essential part of determining fault locations. The expected route of a cable must be identified to allow for an accurate fault location. The routes can be identified through the use of cable records and tracing equipment. The records will be used as an approximation on the location of the cable before equipment can be used to locate the exact location of the cable route. Using the gathered pre-location data and identifying the cable route increases substantially increases the chances of pin-pointing the fault.

A CAT and Genny is typically used to trace LV cables. However, this type of equipment is subject to interference as other underground utilities, different live underground cables and ground make-ups can affect the performance of the cable detection tool. This equipment is only used as a way of indicating a cable route and not as a way of identifying a cable amongst other infrastructure.

\section{E. Pinpointing}

After the pre-location has obtained a good estimate on the faulted area, the next step is to confirm the exact location of a cable fault. The most common pinpointing methods used in SPEN are the acoustic method, cable sniffer method and the dig and test method. SPEN always use the acoustic method to locate faults in the HV network, whereas, the cable sniffing method or the cut and test method is used to locate faults in the LV network.

The LV cable sniffer method is the preferred method of the two as it can reduce fault costs by almost $50 \%$. This method works by sensing and analyzing gases emitted by cable faults. The gases it detects are given off by the breakdown of insulation at the point of fault. A sniffer nozzle is inserted into small $8 \mathrm{~mm}$ bored holes in the surface of the ground to detect and analyze any gases if present,

The sniffer analyses the gases in parts per millions $(50,000 \mathrm{ppm}=$ full scale deflection $)$, the higher the reading means the higher the concentration of gas detected. As the concentration of gas spikes over the point of fault the location becomes pinpointed. This sniffer is limited on following circumstances; when the gas may have dissipated into the air by the time an approximated fault location has been determined; when the makeup of the ground does not allow gas to disperse to the surface; or when the insulation has not broken down enough to release a concentration of gas which can be detected.

The cut and test method is outdated but still often a necessary option in SPEN fault-finding practice, especially when the cable sniffer method is not successful. This method is used in two conditions; the first condition is when a positive prelocation can be determined with the use of a TDR and at the estimated point of fault the cable sniffer method is used, but if it cannot pinpoint the fault location then a cut and test is required; the second condition is when there is no positive fault location given by the TDR and the only way of determining the location of the fault is by sectioning the circuit down until the location of the fault can be found.

Although the cut and test method is very reliable and has been in practice since the start of fault-finding, this is not a desirable technique for SPEN in an economical respect. The issue is that the cost of fault repair may greatly exceed their estimations due to the requirement of multiple excavations. 


\section{F. Cable identification}

Cable identification testing is required for locations where the faulted cable is amongst several others. Clear identification of the faulted cable is crucial before repair work begins in order to maintain safe working practices. Any uncertainty or complacency in the identification of a cable to be worked can lead to a fatality or unplanned outage of another circuit. It is therefore essential, that field staff and engineers are experienced and competent in the identification of underground cables. The cable identification process varies for both $\mathrm{HV}$ and LV cables, the difference in process is from a health and safety standby point; LV cables can have their outer sheath and layers removed, exposing the live cores, which can then be tested live with the appropriate testing equipment; this cannot be done on $\mathrm{HV}$ cables as there is no procedure or equipment available to carry out these tests safely.

Cables are identified in SPEN's LV network by consulting the appropriate cable records to indicate the position of the relevant cable(s) in relation to all other cables, pipes or ducts at the points of work. Past and present practices in respect to cable types, armoring, jointing and depth of laying may provide some degree of identification. If there is only one cable in the track, with no conflicting evidence, the cable may be considered as positively identified without further examination.

\section{G. Repair}

Re-energization of a cable will be done, once all appropriate testing and repairs have been carried out, ensuring the cable is fit to return to service.

\section{PROPOSED LV FAULT-FINDING FRAMEWORK}

In SPEN, there is no designated LV fault-finding process based on a structured protocol. Training in this field is based on gaining valuable experience and knowledge which is handed down from engineers who have become experts in their professions. Yet, limited documentation within SPEN can make it difficult for apprentices and trainee engineers to grasp a deeper understanding. Hence, a framework was developed for the purpose of creating a more methodical structured approach to fault-finding. This is presented in the form of a flowchart detailing the fault-finding procedure for different scenarios. The importance of this flowchart cannot be underestimated as it aims to play a vital role in developing apprentices and trainee engineers within the industry as they can grasp an invaluable understanding of how to locate a fault prior to onsite experience. Furthermore, this documentation can be implemented during the course of a fault occurrence, or even after, to further enhance the learning experience from the processes and methods used. The flowchart is shown in Figure 8.

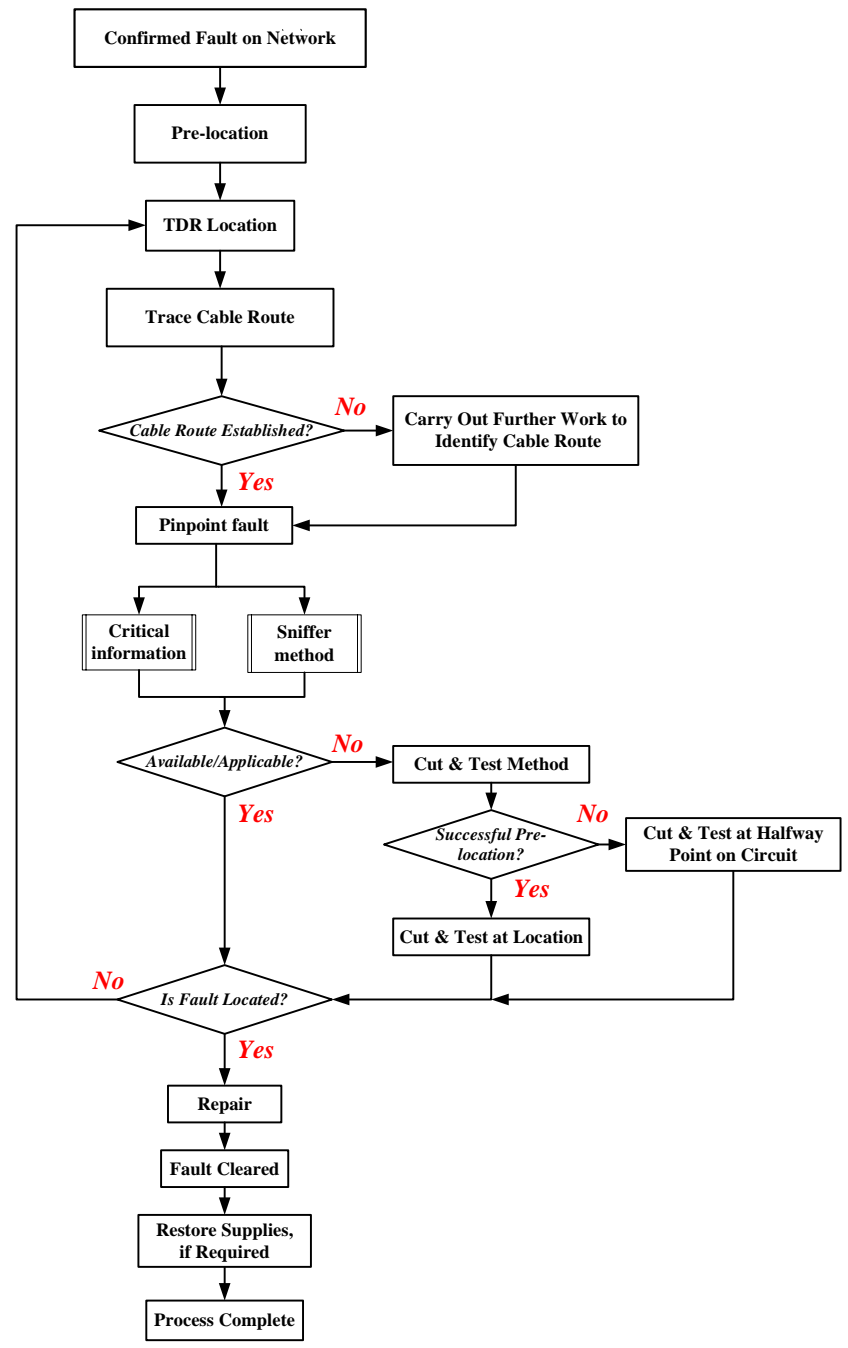

Figure 8. Flowchart presenting the proposed framework for fault-finding in underground cables in LV distribution networks.

\section{DISCUSSION}

The fault location process for SPEN is an intrinsic part of the company. This is because it can economically affect the company through penalties and incentives issued by regulatory bodies. SPEN is a customer driven business which attempts to uphold a high-quality customer service score, therefore, it's important that the processes and methods, as well as the field engineers carrying these techniques, are fast and efficient when locating faults within the distribution network. This in turn, helps to reach a high level of customer satisfaction. The fault location processes and methodologies currently being used at SPEN to date are highly dependent on the experience and knowledge of field engineers who attend the faults. Although a flowchart has been made to create a more methodical structure of LV fault-finding, there is still a lack of an established reliable procedure.

The research revealed that there is a lack of options available for implementing on the LV distribution network because domestic loads limit the applicability of using some of the same techniques which suffice for HV fault-finding. Several techniques employed by $\mathrm{HV}$ fault-finding utilize a process called 'thumping', where high voltage is used to break down the fault resistance through arcing, thereby, creating measurable reflecting pulses as well as a detectable signal in the form of a 'thump' sound and an electromagnetic impulse. 
When used for pinpointing, transducers are employed to trace the signal quickly and with high precision. However, the 'thumping technique is not applicable for LV fault-finding because the high voltage used for thumping can be damaging to the domestic loads connected on the LV network.

The cut and test method is also an outdated procedure used in SPEN, which is very time consuming and costly due to excess excavations, and detrimental to cable design life. As discussed in the introduction of this report, most faults occur to poor workmanship, hence, it seems inevitable that cutting and repairing several sections of the cable will compromise its integrity and make it susceptible to future faults. However, there is no available alternative that can replace this method when a TDR trace or cable sniffer method cannot be used to identify or pinpoint a fault.

Comprehensively analyzing the fault confirming process revealed it to be highly inefficient because the method is totally dependent on external sources (customers) supplying the crucial information required for the response team to acknowledge the potential fault type and location. Although the trouble calls are effective, their dependency on external sources and time-consuming limitations deem them to be an outdated method. The HV network has an integrated supervisory control and data acquisition (SCADA) system to monitor the condition of the protective devices and relays, so in the event of a fault or any network irregularity, real-time data will be instantly processed back to the engineers in their control room potentially informing them on a more localized fault area as well as the type of fault. The fact that the HV network has adopted a superior technological approach is evidence that technology is available to apply on to the LV network as well. However, it could be the case that SCADA is not feasible to apply to the LV network because of its innumerable branching to significantly more customers in proportion to the HV distribution network. Nonetheless, the trouble call method should be updated to a more reliable approach for sufficient, fast and reliable data acquisition.

\section{CONCLUSION}

There is a lack of sufficient LV fault-finding techniques, which is why there is a lack of a methodical approach to LV fault-finding and more dependency on the experience gained by time spent engineers. The seven main steps used to locate faults within the distribution network are: Confirm Fault, Fault Identification, Pre-location, Cable Tracing, Pinpointing, Cable Identification and Repair. From these seven steps, there would be the following recommendations made to SPEN to improve their fault location efficiency. Firstly, it was concluded from the research that the trouble call method used for confirming a fault occurrence on the LV network is an outdated process. It is recommended that SPEN should invest into integrating smart systems, such as SCADA, into their LV network which can identify blown fuses at a substation and notify the control room. This would drastically reduce the time customers spent offline. Furthermore, it is recommended for SPEN to install fault passage indicators to be fitted on all substations as this would result in the faster identification of faulty sections, thereby, reducing the overall time of fault localization.

It was clear from analyzing the processes and methodologies that SPEN should invest into upgrading new-age technologies into their processes to replace the cut and test method and find alternative back-up technologies for occasions when their primary methods are not applicable or unsuccessful.

\section{REFERENCES}

[1]. Health and Safety Executive, "Underground cables, what you need to know", U.K. Government. Available at: https://www.hse.gov.uk/electricity/underground.htm

[2]. Scottish Power Energy Networks, "Distribution Annual Report (2018/19)'”.2019, Available at: https://www.spenergynetworks.co.uk/userfiles/file/32782_SPEN Distribution_Report_2019.pdf?v=1.2

[3]. Zhou, C, Yi, H \& Dong, X 2017, 'Review of recent research towards power cable life cycle management', IET High Voltage, vol. 2, no. 3, pp. 179-187. DOI: 10.1016/j.epsr.2016.12.018.

[4]. Y. Wang, N. Davies, "Reducing failure rates and better management of underground cable networks", EA Technology, T \& D Cable, Dec 2014. Available at: https://www.cablejoints.co.uk/upload/Reducing-Failure-Ratesand-Better-Management-of-Underground-Cable-Networks.pdf

[5]. R. MacKinlay, "Managing an aging underground high-voltage cable network," in Power Engineering Journal, vol. 4, no. 6, pp. 271-277, Nov. 1990, doi: 10.1049/pe:19900054.

[6]. W. Zhao, W. H. Siew and M. J. Given, "The electrical performance of thermoplastic polymers when used as insulation in cables," 2013 48th International Universities' Power Engineering Conference (UPEC), Dublin, 2013, pp. 1-4, doi: 10.1109/UPEC.2013.6714868.

[7]. Mecheri, Yacine \& Bouazabia, Slimane \& Boubakeur, Ahmed \& M.Lallouani, "Effect of thermal Ageing on the Properties of XLPE as an Insulating Material for HV Cables", Conference paper: International Electrical Insulation Conference, IET. Birmingham, UK, 2013

[8]. A. Tzimas, S.M. Rowland, L. A. Dissado, M Fu and U. H. Nilsson. "Effect of Long-Time Electrical and Thermal Stresses upon the Endurance Capability of Cable Insulation Material", IEEE Transaction on Dielectrics and Electrical Insulation, Vol 16, No. 5, (2009) pp. 1436-1443

[9]. Alghamdi AS, Desuqi RK. "A study of expected lifetime of XLPE insulation cables working at elevated temperatures by applying accelerated thermal ageing”. Heliyon. Vol 6,1 (2020), IEEE fault finding tech citations

[10]. M. F. Islam, A. M. T. Oo and S. A. Azad, "Locating underground cable faults: A review and guideline for new development," 2012 22nd Australasian Universities Power Engineering Conference (AUPEC), Bali, 2012, pp. 1-5.

[11]. G. Cheung, Yuan Tian and T. Neier, "Technics of locating underground cable faults inside conduits," 2016 International Conference on Condition Monitoring and Diagnosis (CMD), Xi'an, 2016, pp. 619-622, doi: 10.1109/CMD.2016.7757954.

[12]. X. Yang, M. Choi, S. Lee, C. Ten and S. Lim, "Fault Location for Underground Power Cable Using Distributed Parameter Approach," in IEEE Transactions on Power Systems, vol. 23, no. 4, pp. 1809-1816, Nov. 2008, doi: 10.1109/TPWRS.2008.2002289

[13]. T. A. kawady, A. I. Taalab and M. El-Sad, "An accurate fault locator for underground distribution networks using modified apparent-impedance calculation," 10th IET International Conference on Developments in Power System Protection (DPSP 2010). Managing the Change, Manchester, 2010, pp. 1-5, doi: 10.1049/cp.2010.0302

[14]. Cigre, "Fault location on land submarine links [AC \& DC]", reference TB773, B1 Insulated cables, Sep'19, September 2019

[15]. Megger,"Fault finding solutions", Thorne \& Derrick UK, 2003

[16]. EA Technology. EAT - EATL. CS2 Cable Sniffer, Available at: https://www.eatechnology.com/engineeringproducts/cablesniffer/

[17]. I. V. Bryakin, I. V. Bochkarev and V. R. Khramshin, "Cable Avoidance Tool," 2019 International Russian Automation Conference (RusAutoCon), Sochi, Russia, 2019, pp. 1-7, doi: 10.1109/RUSAUTOCON.2019.8867688. 